\title{
Environmental Responsibility of Coal Mining Companies and Quality of Life Measuring in Mining Clusters
}

\author{
Lyudmila Starikova ${ }^{1,}$, Lyudmila Sagdeeva ${ }^{2}$, and Irina Trapeznikova ${ }^{2}$ \\ ${ }^{1}$ Plekhanov Russian University of Economics, Kemerovo branch, 650992, 39, Kuznetskiy prospect, \\ Kemerovo, Russia \\ ${ }^{2}$ Kemerovo State University, 650000, 6 Krasnaya St., Kemerovo, Russia
}

\begin{abstract}
The development of coal mining in the largest Russian mining cluster - Kuzbass (Kemerovo Region, Western Siberia) is accompanied, on the one hand, by an increase in environmental issues in the form of air, water and soil pollution. The same applies to the growth of coal processing in the region - coal preparation, coke and coal chemistry production. On the other hand, the well-being of the population of the region in which clusters of coal and coal chemistry are located is growing. Therefore, the responsibility of coal companies to the regional community acquires a dual meaning ecological and socio-economic. Assessing such responsibility of coal companies requires the formation of a special approach to identifying the impact of mining development on the quality of life of local communities.
\end{abstract}

\section{Introduction}

The world scientific community has been studying the quality of life as the basic basis of human development for a long time and in various aspects. The definition of the concept of "quality of life" is given, its volume and maintenance are defined, the rating of regions on quality of life is carried out [1].

In all aspects of research, the most significant factor that has more or less influence on any aspect of the consideration is the state of the environment or environmental factor. It is proved that there is a close connection between the level of pollution of water, air and such medical and biological indicators as the increase in morbidity, reduced human development, deterioration of the parameters of the functioning of natural and artificial ecosystems. According to World Health Organization (WHO): "Urban residents are exposed to a range of environmental threats that are associated with the lack of adequate housing and transport, as well as poor water quality, sanitation and waste disposal. Nearly $90 \%$ of the world's urban population breathes air that does not comply with WHO air quality guidelines." [2] But, despite the obvious relationship between the quality of life and the quality of the environment, the assessment of the quality of housing as a habitat is poorly associated with this factor and in the practice of assessing the value of residential real estate is not reflected.

\footnotetext{
* Corresponding author: $\underline{\sin 55 @ \text { list.ru }}$
} 
The areas of presence of coal mining enterprises are the regions characterized by a high level of environmental and anthropogenic load. The task of the coal business is to work within the framework of social responsibility according to the requirements of the modern international market. It is necessary to assess the quality of life of the population for compliance [3].

In terms of property valuation, an environmental factor is understood any natural phenomenon or qualitative state of the environment and its individual components, as well as the qualitative state of the real estate elements themselves, affecting the market value of real estate. For example, environmental factors include such conditions and parameters of the environment as the level of pollution of the main natural environments - water, air, soil, including radioactive pollution; the presence of a beautiful view, the presence of green areas, an attractive architectural environment, the presence or absence of nearby landfills, the presence or absence of a number of not-pleasant, not attractive industrial facilities (e.g., incinerators) and, all in all, our idea of the quality of the environment. The quality of the housing include the area, layout, wall material, availability of sanitary and communal services, noise, hydro, vibration insulation, insolation and other characteristics.

Thus, there are two approaches are possible, depending on the task of assessing the impact of environmental factors on the cost of housing relative to the scale and level of accuracy of the calculations.

The first is focused on a rather deep and detailed study of all considered eco-logical and economic issues, which, in its turn, will require significant costs in connection with the involvement of specialists in related industries (ecologists, hydrometeorologists, specialists in corrosion protection and sanitary hygiene, etc.).

The second approach is based on the possibility of using a specialist-appraiser normative reference information that allows to carry out calculations to assess the impact of environmental factors on the value of real estate independently.

The article considers the second option of calculating the impact of environmental factors on the quality of housing, and, consequently, the quality of the territory of residence.

\section{Materials and Methods}

The traditional method of real estate valuation has already developed and received legislative consolidation and application [4]. But the issue of taking into account the environmental component remains out of the field of view of both normative documents and the practice of assessment. It is necessary to find a method of extracting from the value of the property (e.g., apartments or houses) a share related to the value of the environmental factor, as well as to determine the function of the demand for the quality of the environment and the quality of housing in order to obtain an economic estimate of the cost of its improvement [5]. This indicator can be used as an inverse value of environmental damage.

Statistical methods and hedonistic method are used to evaluate residential real estate objects taking into account environmental factors in the framework of comparative, income and cost approaches.

Using the methods of comparative approach, environmental factors are considered as elements of comparison, and their impact on the cost is determined by making adjustments to the prices of similar objects. The number of elements of comparison related to the environment can be quite large, and their choice is determined by the availability of reliable and available information as elements of comparison, you can use the quantitative and qualitative characteristics of the selected elements of comparison.

The hedonistic method is a type of preference assessment in which market-oriented prices are used to determine the prices of invaluable goods and services. The advantage of the method based on the processing of statistics, expressed in the law of large numbers, is that the patterns are manifested only in a sufficiently large number of units (cases). 
The deviation of these individual units in both directions from the General pattern of all the effects caused by accidental causes, at a sufficiently large number of units are almost repaid. In any mass phenomenon, along with factors common to the whole mass of units, there are random factors, that is, those that can be different in individual units, and their action can be directed in different directions. While applying the hedonistic method as a result of mutual cancellation of the action of random factors, the action of significant factors is manifested.

Using statistical techniques, the hedonic approach allows:

1. To determine how much the value of real estate and land depends on the differences in the characteristics of the environment.

2. To determine how many people are willing to pay to improve the quality of the environment.

At the first stage of the evaluation procedure using the hedonistic method, we determine the admissibility of the application of this method. The criterion of admissibility is the following parameters:

- the real estate market of Kemerovo is active, there are a large number of transactions of purchase and sale;

- there are the ecologically motivated preferences of consumers;

At the second stage, we select the object of study to assess the value of real estate. Onebedroom apartment in a panel house in the secondary housing market of the city of Kemerovo was accepted as a unit of the survey, due to the fact that it is the largest segment $(43.2 \%)$ in the structure of apartments in apartment buildings and (27\%) in individual houses.

At the next stage of evaluation, significant factors that can affect the cost of the selected object of study were identified. Such factors were the following:

- the floor where the apartment is located on;

- transport accessibility (availability of transport near the house);

- air pollution in the area of the object;

- noise level in the area of the apartment;

- the presence of green spaces in the area of the object of study.

At the fourth stage of the study, a calculation tool was selected. Determination of the effect of changing the value of the property depending on differences in the level of contamination was carried out using methods of multiple regression. In our calculations, we use a hedonic price function that describes the balance between the price of real estate and its components.

At the fifth stage of the study, the calculation and analysis of the results were carried out.

\section{Results and Discussion}

The extent of demand for these properties depends on how favorable the environmental situation is in the territory where, for example, a house or office building is located. Consequently, the cost of these objects directly dependents on the level of atmospheric, noise and other environmental pollution of these objects of natural and anthropogenic environment.

Conditionally environmental factors affecting the cost of residential real estate can be divided into 2 groups: quantitative and qualitative.

Quantitative indicators include the measured characteristics of the natural environment (air pollution index, noise level, radiation level, electromagnetic pollution, etc.).

Quality indicators include environmental and natural characteristics related to location. Such characteristics can be expressed in descriptive or verbal form (such as landscaping, clutter).

For this study, the following environmental factors were identified: quantitative - the level of noise exposure and air pollution index, qualitative - it is provided with green spaces. 
Kemerovo is located in the zone of increased potential of air pollution. Historically, the existing hollow position of the town with an open exit only to the North-West with prevailing South-West winds determines the increased potential of air pollution - Figure 1 [6-7].

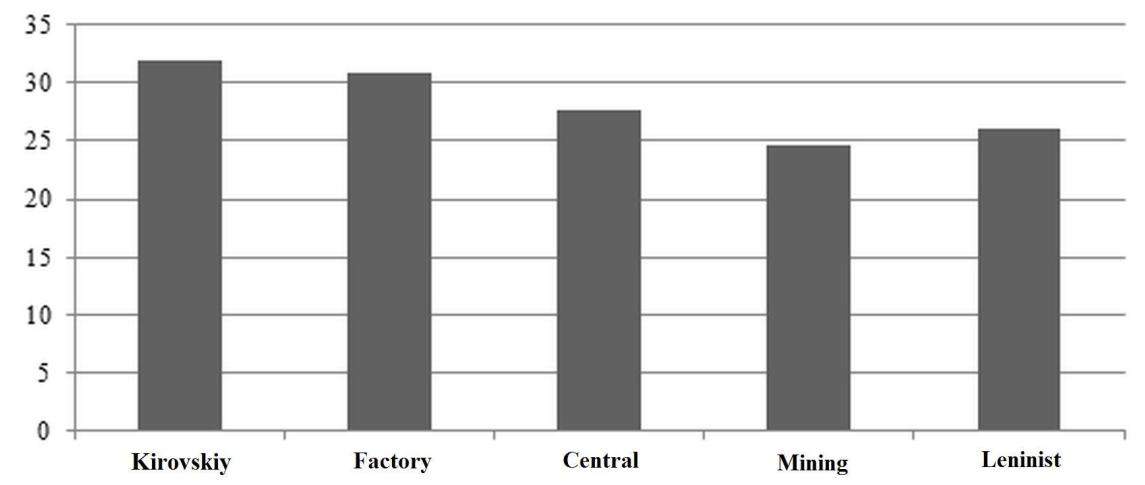

Fig. 1. An integral index of pollution of atmospheric air, calculated for the regions of Kemerovo in 2017.

To assess the state of the air environment in the districts of the city of Kemerovo, the data on the average annual concentrations of pollutants in the air for 2017 were used. Then, air pollution indices for each pollutant were determined, the data obtained were grouped by districts of Kemerovo and the integral air pollution index in each district of Kemerovo was calculated.

Thus, the areas with a relatively low level of air pollution are Mining and Leninist districts of Kemerovo. The areas with high levels of air pollution are Kirovskiy and Factory districts.

Another environmental pollution is acoustic pollution. According to the study, "noise pollution", which is now characteristic of large cities, reduces the life expectancy of their residents by 10-12 years. The negative impact on people from the noise of the metropolis is $36 \%$ more significant than from tobacco smoking, which reduces human life by an average of 6-8 years.

Noise is random fluctuations of different physical nature, characterized by the complexity of time and spectral structure. The human body reacts differently to noise of different levels. Noise levels of 70-90 dB with prolonged exposure lead to diseases of the nervous system, and more than $100 \mathrm{~dB}$ - to hearing loss, up to deafness [8].

Therefore, while planning and constructing of urban and rural settlements, design, construction, reconstruction and operation of production facilities, the creation and development of new equipment, production and operation of vehicles, measures must be developed to ensure compliance with the standards of permissible physical impacts and, in particular, acoustic pollution. Permissible sound levels and sound pressure levels in octave frequency bands and sound levels in residential areas, residential and public buildings are regulated by sanitary norms.

The analysis of the maximum noise levels on the territory of residential buildings in the daytime was carried out. The found data were analyzed and grouped by districts of Kemerovo (Tab. 1). 
Table 1. Maximum one-time values of the noise level in the districts of Kemerovo

\begin{tabular}{|c|c|c|}
\hline $\begin{array}{c}\text { Name of } \\
\text { district }\end{array}$ & $\begin{array}{c}\text { Maximum noise } \\
\text { level, Lmax, } \mathbf{~ d B a}\end{array}$ & $\begin{array}{c}\text { Permissible maximum noise } \\
\text { level, dBa } \\
\text { (CH 2.2.4/2.1.8.562-96. 2.2.4) }\end{array}$ \\
\hline Factory & 94.8 & 70 \\
\hline Kirovskiy & 92.3 & 70 \\
\hline Central & 83.4 & 70 \\
\hline Leninist & 79.15 & 70 \\
\hline Mining & 76.1 & 70 \\
\hline
\end{tabular}

In all areas of the town, without exception, there is an excess of permissible maximum noise levels. The highest values were recorded in the Factory and Kirovskiy districts. Lower - in the Mining and Leninist districts.

In a later GOST R 54954-2012 equivalent and maximum levels of sound and penetrating noise must not exceed the maximum permissible sound level in rooms and apartments in the daytime during the day $55 \mathrm{~dB}$, at night - $45 \mathrm{~dB}$. At the same time, the permissible noise levels generated in residential premises by ventilation systems and other engineering and technological equipment must be lower by $5 \mathrm{dBA}$ of these levels during the day and night. Taking into account modern requirements, the noise level exceeds the permissible 2 times.

In the system of urban greening, the main environmental role belongs to public plantations. Public green spaces are the most important indicator of the degree of greening of the city. The common green areas include urban forests, forest parks, parks, gardens, squares, boulevards, as they are intended for recreation of the urban population.

According to the Department of life support under the administration of Kemerovo [9], the area of public green areas within the city limits is 618 hectares, which is much lower than the established norms, almost 2 times for cities of this level (12 against $24 \%$ ).

The maximum area of common use plantations is noted in the Mining district of the town - 318.11 hectares (due to the territory of the natural Park "Rudnichny Bor"), followed by the Central district - the area of common use plantations (including the city garden, parks, squares, boulevards, green areas and flower beds) - 86.77 hectares, in Kirovskiy - 33.77 hectares, in Leninist - 21.56 hectares, and the smallest area of green areas of common use, and, consequently, the provision of residents with green plantations - in the Factory district -21.56 hectares. 14.1 hectares (Tab. 2).

Table 2. Provision of residents with green areas in different areas of Kemerovo.

\begin{tabular}{|c|c|c|c|c|c|}
\hline $\begin{array}{c}\text { Name of } \\
\text { district }\end{array}$ & Area & Population & \multicolumn{2}{|c|}{$\begin{array}{c}\text { Area of green } \\
\text { areas of common } \\
\text { use }\end{array}$} & $\begin{array}{c}\text { The size of } \\
\text { the green } \\
\text { area of the } \\
\text { district }\end{array}$ \\
\cline { 4 - 6 } & & & hectars & $\begin{array}{c}\mathbf{m}^{\mathbf{2}} \text { per } \\
\text { capita }\end{array}$ & $\%$ \\
\hline Factory & 9120 & 90448 & 318.11 & 65.32 & 3.5 \\
\hline Kirovskiy & 1250 & 102528 & 86.77 & 6.80 & 6.9 \\
\hline Central & 7000 & 59297 & 33.77 & 5.27 & 0.5 \\
\hline Leninist & 2200 & 141001 & 21.56 & 1.43 & 1.0 \\
\hline Mining & 8660 & 153885 & 14.10 & 1.32 & 0.2 \\
\hline
\end{tabular}

Environmental factors using the comparative approach are considered as elements of comparison, and their impact on the cost is determined by making adjustments to the prices of similar objects. We applied the following adjustments: adjustment for the availability of green space in the area; adjustment for the noise level in the area; adjustment for the air quality in the area. 
Thus, as a result of the assessment, we came to the conclusion that the use of traditional adjustments: the location of the object, the quality of finishing, the material of the building, the presence of additional improving conditions led to a decrease in the cost of $1 \mathrm{~m} 2$ by an average of 1571.87 rubles, and the application of adjustments taking into account environmental factors of the environment in which the object is located led to a decrease in the cost of $1 \mathrm{~m}$ by an average of 5008.93 rubles.

This method of assessment can be applied in the structure of ratings of municipal districts in the regions and for comparison of subjects of the Russian Federation.

The research base of similar apartments located in different areas of Kemerovo was formed to assess the impact of environmental factors on the cost of real estate hedonistic method. The database includes only two-bedroom apartments, arranged in 5 and 9-storey panel houses built no later than 2000. Thus, the research base made up to 100 such apartments.

For the analysis of connections of the considered factors the matrix of pair correlations was constructed (Tab. 3).

Table 3. Matrix of pair correlation coefficients.

\begin{tabular}{|l|c|c|c|c|c|c|}
\hline \multicolumn{1}{|c|}{ Element } & $\begin{array}{c}\text { The } \\
\text { cost of } \\
\mathbf{1 ~ m}^{\mathbf{2}}\end{array}$ & $\begin{array}{c}\text { Distance } \\
\text { from } \\
\text { public } \\
\text { transport }\end{array}$ & $\begin{array}{c}\text { Floor } \\
\text { location } \\
\text { of the } \\
\text { object }\end{array}$ & $\begin{array}{c}\text { Provision of } \\
\text { the area } \\
\text { with green } \\
\text { spaces }\end{array}$ & $\begin{array}{c}\text { Air } \\
\text { quality } \\
\text { in the } \\
\text { area }\end{array}$ & $\begin{array}{c}\text { Noise } \\
\text { level }\end{array}$ \\
\hline The cost of $1 \mathrm{~m}^{2}$ & 1 & & & & & \\
\hline $\begin{array}{l}\text { Distance from } \\
\text { public transport }\end{array}$ & 0.98389 & 1 & & & & \\
\hline $\begin{array}{l}\text { Floor location of } \\
\text { the object }\end{array}$ & 0.97101 & 0.58807 & 1 & & & \\
\hline $\begin{array}{l}\text { Provision of the } \\
\text { area with green } \\
\text { spaces }\end{array}$ & 0.93866 & 0.64739 & 0.35741 & 1 & & \\
\hline $\begin{array}{l}\text { Air quality in the } \\
\text { area }\end{array}$ & 0.93078 & 0.537992 & 0.34273 & 0.88251 & 1 & \\
\hline Noise level & 0.90557 & 0.811935 & 0.3122 & 0.8561 & 0.8937 & 1 \\
\hline
\end{tabular}

The analysis of paired correlation coefficients shows that all the factors: the floor location of the apartment, the remoteness of the apartment from public transport stops, the quality of the air, the noise level and the provision of green space in the area of the apartment location, have a close relationship with the effective - the cost of 1 square meter of housing. The greatest strength of the connection of the first factor is the floor where the apartment is located on, and the second factor is the distance from the public transport stop, the pair correlation coefficients are 0.984 and 0.971 , respectively. Most of the factors have a reliable relationship with each other. However, the comparison of paired correlation coefficients shows that the dependence of factors on each other is lower than the relationship of factors with the effective one. With the help of correlation and regression analysis the regression equation is obtained (1).

$$
Y_{X}=2292,51-1,03 x_{1}-0,27 x_{2}+0,67 x_{3}-2,1 x_{4}-1,26 x_{5} R^{2}=0,96
$$

Thus $Y_{x}$, the cost of $1 \mathrm{~m}^{2}$ of residential real estate in Kemerovo is significantly affected by the remoteness of the apartment from public transport, the floor where the apartment is located on, the security of the area of the apartment with green spaces, the quality of the air and the noise level. It was established a reliable connection between the cost of residential real estate in Kemerovo and environmental factors of the urban environment. 
Thus, the higher the degree of pollution, the lower the average cost of $1 \mathrm{~m}^{2}$ of residential real estate in the industrial areas of the town, which include Factory and Mining areas. The exception is the average cost of $1 \mathrm{~m}^{2}$ of housing in the Central district of Kemerovo with a high level of pollution (Tab. 4). This indicates that both sellers and buyers have no clear distinctions in the assessment of average and high pollution, as well as with the influence of factors such as infrastructure development.

Table 4. The average price per $\mathrm{m}^{2}$ of residential real estate, taking into account environmental factors by districts of Kemerovo.

\begin{tabular}{|c|c|c|c|c|c|}
\hline $\begin{array}{c}\text { Name of } \\
\text { district }\end{array}$ & $\begin{array}{c}\text { Pollution } \\
\text { level of the } \\
\text { area }\end{array}$ & $\begin{array}{c}\text { Average price per } \\
\mathbf{1} \mathbf{~ m}^{\mathbf{2}} \text { excluding } \\
\text { adjustments, } \\
\text { rubles }\end{array}$ & $\begin{array}{c}\text { The average price per } \mathbf{1} \\
\mathbf{m}^{\mathbf{2}} \text { taking into account } \\
\text { the environmental } \\
\text { factor, rubles }\end{array}$ & $\Delta$ cost, rubles & $\begin{array}{c}\Delta \text { cost, } \\
\%\end{array}$ \\
\hline Factory & Average & 47897.09 & 46469.75 & 1427.33 & 3.0 \\
\hline Kirovskiy & Average & 47533.36 & 41611.89 & 5921.47 & 12.5 \\
\hline Central & High & 49529.44 & 42730.92 & 6798.52 & 13.7 \\
\hline Leninist & Upper high & 37994.24 & 30698.40 & 7295.84 & 19.2 \\
\hline Mining & Upper high & 40366.71 & 30164.83 & 10201.88 & 25.3 \\
\hline
\end{tabular}

\section{Conclusion}

The obtained data can be characterized as damage to the population due to the non-pleasant environmental situation. But do people realize this fact?

To clarify the attitude of residents to the quality of housing, LLC "Center of hygienic expertise" conducted a sociological survey from 10 to 26 September 2014. A total of 2007 respondents were interviewed in Kemerovo region. The error does not exceed $1.3-2.2 \%$. According to the survey, $63,4 \%$ of inhabitants of Kemerovo region don't think about the effect of housing environment on their health. The determining factor in the choice of housing is the price, said $97 \%$ of respondents. $85 \%$ of respondents do not associate the emergence or exacerbation of chronic diseases with the ecology of housing. Thus, today the issue of housing quality takes a back seat. At the same time, $9.6 \%$ of the surveyed residents of the region responded that they have diseases caused by the adverse effects of construction, finishing materials and furniture. $50.7 \%$ of them had respiratory diseases, $24.7 \%$ - disorders of the cardiovascular system, $21.1 \%$ - allergies, $7.6 \%$ - diseases of the nervous system.

At the same time, the calculated value of the environmental factor of housing quality should be compared with the costs of environmental activities that prevent damage to residents. This amount can be considered by construction companies or the city administration as an economically justified amount of funds for environmental activities, which will achieve environmental well-being.

The hedonistic assessment of the quality of housing, taking into account the quality of the environment, can be used not only for the formation of the housing strategy of the population, construction companies and city authorities, but also for the further development of other methods of assessing the quality of life.

The study was conducted in the framework of the master thesis Y. A. Arcasoy. 


\section{References}

1. S. N. Bobylev, The human development report in the Russian Federation for 2013 (RAILF Pub., Moscow, 2013)

2. Towards a healthier and safer environment (World Health Organization, Washington, 2017)

3. L. S. Sagdeeva, L. N. Starikova, Crisis of the economic system as a factor of instability of modern society (SGU Press., Saratov, 2013)

4. The Federal valuation standard "Valuation of real estate" (FVS \# 7) (Ministry of Economic Development of Russian Federation, Moscow, 2014)

5. L. M. Butler, Ecological component of economic valuation of real estate (MSU, Moscow, 2006)

6. L. S. Sagdeev, I. S. Trapeznikova, Analysis of interrelations between indices of human development and unfavorable ecological situation (on the example of the Kemerovo region) (Eurasia, Barnaul, 2007)

7. L. S. Sagdeeva, The Impact of public health on the human resources of the region (Business Kuzbass, Kemerovo, 2011)

8. D. Gakaev, Young Scientist, 15, 261-264 (2015)

9. General plan of the City Kemerovo development up to 2032. URL: http://www.mgis42.ru/ 